\title{
Facade Retention Accomplishments in View of Ergonomic Design
}

\author{
Jerzy Charytonowicz and Maciej Skowronski \\ Wroclaw University of Technology, Faculty of Architecture, \\ ul. B. Prusa 53/55, 50-317 Wroclaw, Poland \\ \{jerzy.charytonowicz, maciej.skowronski\}@pwr.wroc.pl
}

\begin{abstract}
Both individual buildings and large complexes of buildings that are now being adapted or revitalized may have been withdrawn from using due to some general economic tendencies progressing, as well as in consequence of technical deterioration of the given object or just not being able to keep up-todate maintenance standards. These objects, although appreciated for their monumental value and favorable location near the center of a big city, may easily fall into ruin if they are not properly used and maintained. The reconstruction and modernization of the interiors in such buildings, with the original facade retained- which sometimes is a necessary condition imposed by the local planning authorities- may be a chance to restore the building functionality and thus avoid the costly, energy- consuming demolition.
\end{abstract}

Keywords: facade retention, facade technology, ecology, re- use, sustainable design.

\section{Introduction}

The beginning of 21 st century is characterized by a visibly growing popularity of ecofriendly solutions in architecture. This results from more and more strictly defined legislative requirements concerning the parameters applied to the maintenance and construction of buildings, as well as in consequence of a more recognized exploitation of natural environment, which from the beginning has inevitably accompanied the industrial revolution and in the long run may bring disastrous effects. As for the leading design tendencies in contemporary architecture, one of the leading trends is the reusing of materials and existing building structures, which is sometimes performed as the architectural adaptation.

The range of the jobs done within the adaptation may involve: the retaining of the original construction and functional systems, along with the simultaneous modernization of the inner installations and the replacement of finishing materials; the retaining of both the external walls and the main load-bearing structure with the functional system changed, all installations modernized and finishing materials replaced; the retaining of all external walls and modernization of the existing bearing structure in order to adapt the object to its new function; the retaining of all external walls or only selected ones (for tenement houses usually front facades only) along with a 
complete replacement of the inner functional and bearing system, which is the main issue discussed in this paper. The decision of how much we can interfere in the building structure depends on the technical condition of the object, as well as the time of its construction and the kind of a new function planned for it which is usually different that the original one.

While re-using the external masonry walls, one should consider a number of different technical and ergonomic factors of the adaptation process combined. It is essential to choose appropriate solutions, such as: a proper kind of the steel system to stabilize the existing façade or building envelope, while a new bearing system is being founded- as this guarantees a safe using of the object in the future, as well as the comfort and safety of the work being done at the moment (like the manoeuvre space big enough within the building site), only minimal negative impact on the closest surrounding in the vicinity of the investment (i.e. noise, dust, the freedom of transport hampered, the safety of pedestrians influenced, etc.). What seems equally important is the influence of the re-consumption process on the quality and aesthetic value of the space being created, as well as the need to preserve a compact urban tissue and the comfortable using of the interiors according to the contemporary standards (acoustic and thermal insulation, energy consumption, etc.).

Both individual buildings and large complexes of buildings that are now being adapted or revitalized may have been withdrawn from using as a result of some general economic tendencies progressing, as well as due to the technical deterioration of the given object or not being able to keep up-to-date maintenance standards. These objects, however, may have a monumental value and are often located in the vicinity of a big city center. The potential possibility to change the way of using and a thorough modernization of the object is often regarded as the dominant factor while making a decision about retaining the whole existing object or just a part of it.

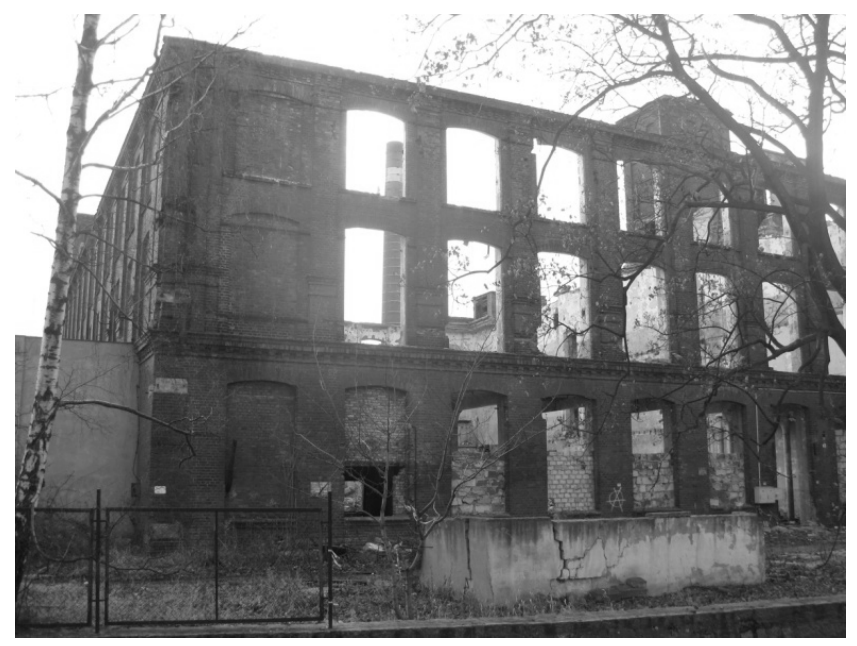

Fig. 1. This is what was left after the textile factory "Silesiana" at Dzierzoniow in Lower Silesia, Poland. The object is to be adapted for a shopping and leisure center (Source: Author's photography of December 2012) 


\section{Advantages Resulting from the Re-using of External Masonry Walls}

The decision to re-use the existing external walls in their original location may bring some substantial advantages as it allows to:

- Achieve the eco-friendly character of the investment as the exploitation of non-renewable resources can be reduced, as well as the consumption of energy and pollution resulting from the manufacturing and transport of the building materials. Another positive aspect is that the amount of waste can be limited, as well as the transport and dumping of the waste. The study carried out by the scientists from the University of Loughborough referring to a typical building in the city center (a brick building situated in the center of London built in 1930, the dimensions of the front wall: $\mathrm{H} 25 \mathrm{~m} \times \mathrm{L} 85 \mathrm{~m}$ ), show that the total amount of the energy needed to construct a new facade is four or even five times bigger than the amount of energy needed for the preserving and restoring of the existing wall [1];

- Reduce to a minimum the negative impact on the surrounding, which seems specially important in view of the ergonomic aspect, as the re-using of the existing building envelope makes it possible to reduce the noise and dust usually created while the demolition involving the crushing of the building elements is being performed. This is essential for a comfortable using of the space in the city center. Usually, the investments of this kind are situated in a close vicinity of other objects, very near or just in the middle of the town center;

- Gain a higher score in the building assessment tools, such as LEED or BREEAM. The possibility of being included in the certification systems in Poland is still a rare occurrence. The PLGBC (Polish Green Building Council) is presently working to adapt both systems mentioned to the Polish conditions [2]. Yet, even now one can observe a growing interest in these issues by Polish investors, as well as the potential users and the media. The buildings that have been given the certificate are usually sold or rented very quickly as this guarantees a low cost of maintenance. What should also be considered is the creating of a positive image of the investor as the one who cares about the natural environment;

- Achieve a representational character of the building through exposing the originally used, traditional and often valuable elevation materials. This makes it possible to take advantage of the representational character of the building while designing objects planned as the residences of important financial institutions, such as banks, offices, or luxury hotels and galleries (See: Fig. 2);

- Preserve the character and compactness of the urban tissue in the area near the existing building whose interior has been irreversibly destroyed due to not having been used for a long time;

- Save the architectural monuments in order to create a modern space that meets the needs of its users while preserving the cultural heritage embodied in the urban system of historic merit. In extreme cases, the building work involves the deconstruction and restoring the original facade (with the use of new materials, hardly any the original ones). It may happen that the preserving of the front elevation unchanged, or at least a part of it untouched, was officially demanded by the local planning authority. The historic- merit facade to be re-used poses numerous restrictions limiting the work being done; 
- Use the whole inner space of the building effectively and profitably. The problems, such as inappropriate story-height or anachronistic construction system can make it difficult to adapt many of the existing buildings to the contemporary requirements. Having demolished the inner system, one usually finds it possible to adapt the object for the new function allowing that contemporary standards and design trends are respected. When the front wall is saved, it is still possible to build additional underground levels which can be used for arranging services, car parks, etc. there;

- Obtain a bigger potential space than in new buildings designed according to the requirements of the local authorities (when the stories are high one can arrange the mezzanine between them), which creates extra profits for the investor;

- Apply for different grants and financial support given by public funds, which eventually may significantly lower the total cost of the investment;

- Take advantage of the simplified administrative procedure necessary to validate the design documentation in some European countries, e.g. in Scotland- according to the Town and Country Planning Act 1990, it is not necessary to obtain the planning permission when the outer walls are preserved, although the inner functional and construction systems have been rebuilt [3].

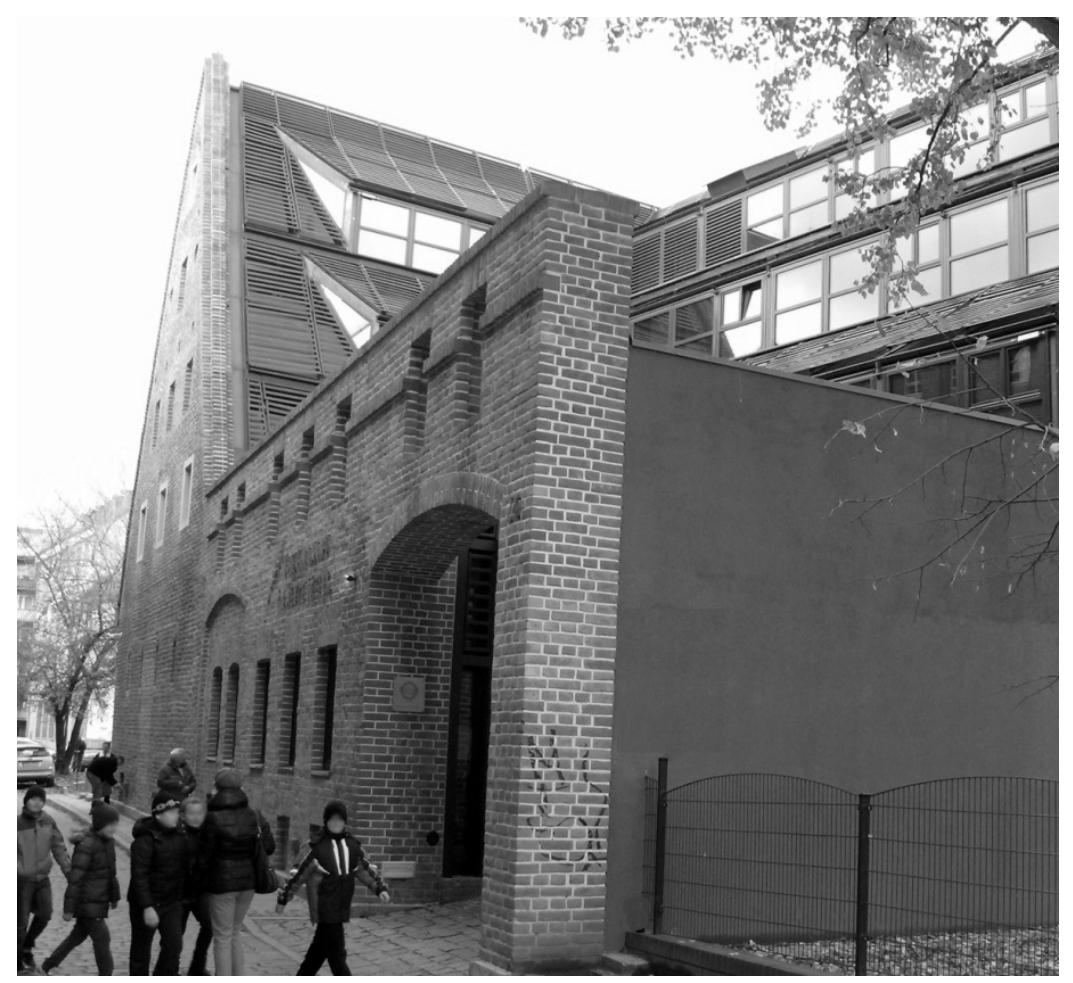

Fig. 2. The Granary La Suite Hotel, Wroclaw, Poland (Source: Author's photo of December 2012) 


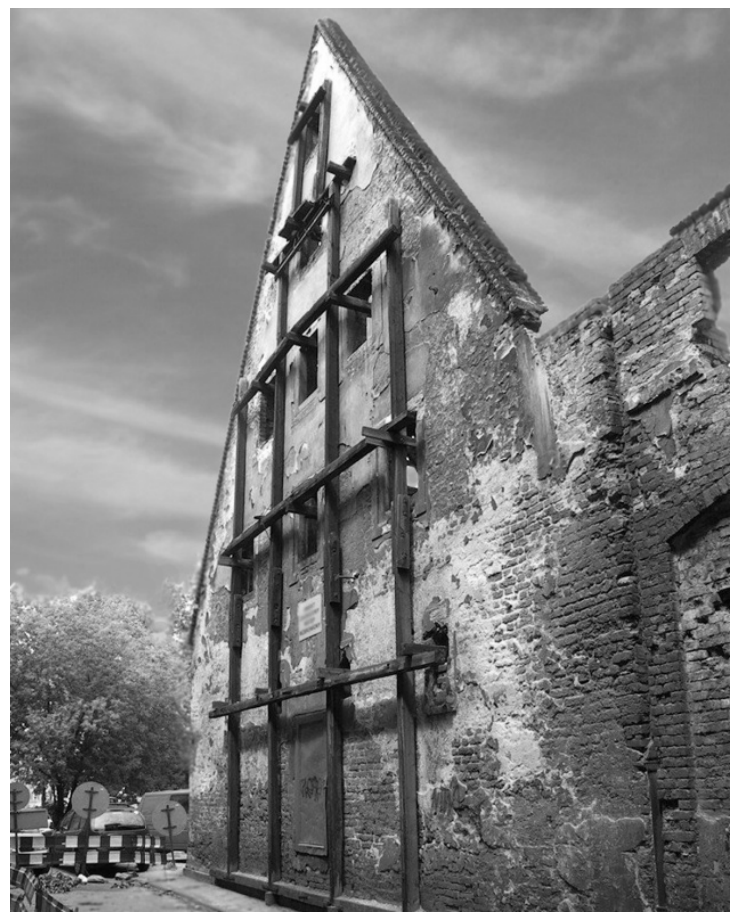

Fig. 3. The front façade of the Granary La Suite Hotel-view on site before re-use (Source: Author's photo of May 2005)

\section{Safety and the Best Possible Solutions for the Building Work Carried Out}

One of the main technical problems while carrying out the retaining process of external walls is the necessity to build a temporary stabilizing construction, as well as the choosing of the appropriate method to connect the existing facade to a new bearing system and making the foundation of the preserved masonry walls strong enough to keep them firmly while the newly designed elements are being settled down in the close vicinity of the existing part of the object. The operation whose aim is to retain the outer partitions of the object is usually begun by the stabilizing of individual building elements. The quality of this phase significantly influences the safety and effectiveness of the further adaptation work. With the stabilizing system properly chosen one can rebuild the interior totally, as well as the ceilings and the whole inner construction of the building. Facades can be supported with various configurations of frame and brace systems. In most cases these are steel systems made to measure which should be conformed to the specific qualities of the groundwork, the height and method of renovation work, as well as other factors determined by the location of the building site. Those jobs are mostly done by specialist's building companies. 

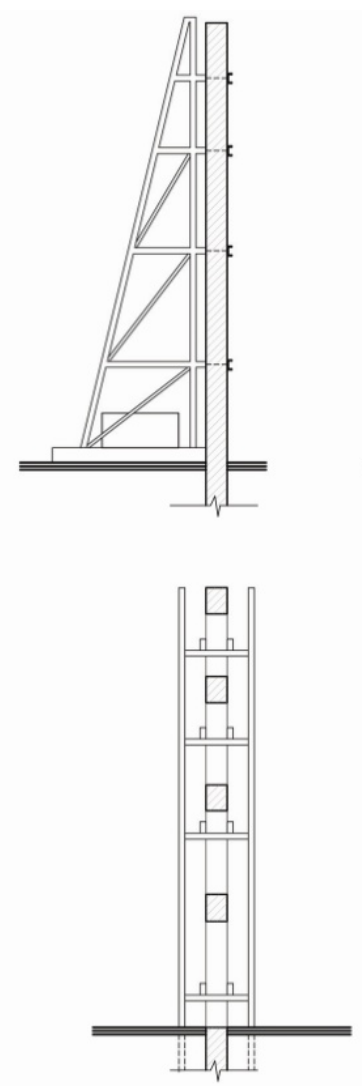
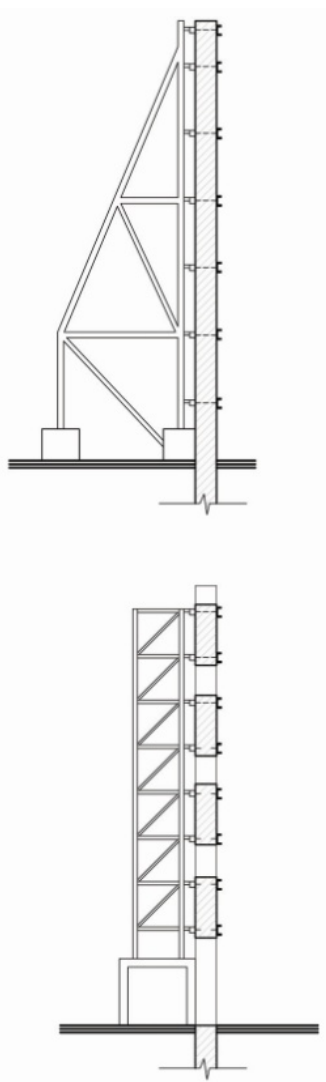

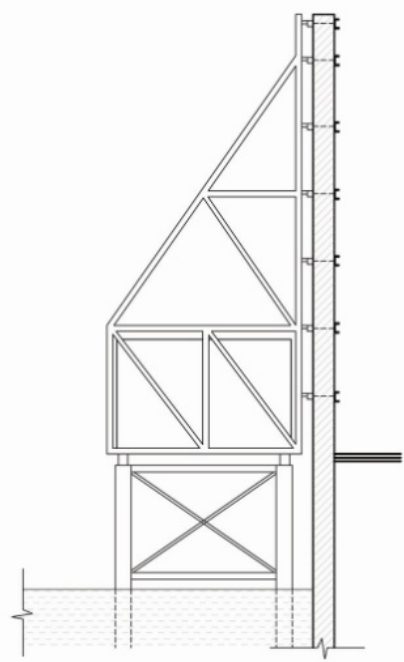

Fig. 4. Exemplary constructions of the steel stabilization systems [4]

As the investments may be located differently, the temporary supporting structures are made as either the outer or inner ones. For individual cases a mixed type can be applied. The outer systems offer some advantages, such as minimal problems while the demolition of the original construction is being done and a new bearing system constructed. The inner supports make the building process somehow more complicated. Yet, there are some advantages too, such as the fact that those supports are situated straight in the place of the investment and do not hamper the pedestrian and vehicle traffic. Thus, there is no need to obtain the permit for occupying the road or sidewalk, which allows for a quicker and more effective investment process done in a big town center. The systems constructed to stabilize the walls during the building work must be based on a good temporary foundation. This functions as a ballast for the whole construction preventing from its possible lifting or moving to the side.

Some design solutions are fairly innovative as the strengthening steel-systems make it possible to reduce the consumption of the so-called 'embodied energy' and limit the cost normally generated by the necessary stabilization of masonry walls. The possibility to achieve the expected factors during the work being done should be considered as early as at the design-stage when one of the possible procedures should be taken into account: 
- While the building work is being done, the steel construction of the future object of destination serves as a stabilizing system for the saved external walls;

- The facade of the building is supported by keeping some of the internal bearing walls saved. The strengths affecting, as well as the horizontal elements of the temporary system are stretched between selectively saved internal walls, which makes it possible to avoid erecting the very costly steel towers of the security system;

- Having been disassembled, the foundation of the temporary construction is used for settling down the bearing elements of the object of destination [1].

While designing the temporary stabilizing construction, one should consider the following conditions:

- The power of wind affecting the facade, as well as its supports (to calculate this one should take the outline of the elevation area measured including the window openings which are usually walled up). In those calculations the two-direction action of the wind should be predicted;

- The need to maximally reduce the negative impact of the construction work on the close surrounding of the building site, such as disturbances in transport; it is also necessary to guarantee the safety of pedestrians, and- in order to reduce the noise and dust- keep the windows bricked up;

- The forces that may result from a possible collision of vehicles crashing into a lower part of the system supporting the wall (it should be emphasized that the supporting construction must be properly lit and marked with proper signs);

- Other local factors which can cause some elements of the construction to be bent or declined;

- An appropriate safety co-efficient in order to prevent the foundation of the temporary construction from sliding down or shifting;

- The necessity of a regular technical check-up and conservation within the temporary bearing construction (the examination of the existing elements with their supports ought to be done regularly, and some extra check-ups should be taken up if necessary, especially when the weather conditions worsen significantly);

- The aspiration to achieve an optimum shape and ideal spacing of the supports while keeping a free access to the existing elements to make it possible for heavy building machines to move freely and avoid any possible collisions while constructing the final-destination frame of the new building. Good access to the adapted cladding walls for the workers carrying out installation and assembling jobs, as well as stock-taking and permanent monitoring of the building elements, installing new joinery, flashings, repairs and maintenance of sub-assemblies when necessary.

\section{The Comfort of Using}

To use the object safely and comfortably, with the aesthetic value preserved throughout the many years of its maintenance, some specific technological solutions assumed at the designing stage of investment, including the assembling instructions, should be carried out. What specially should be guaranteed is the proper connection of the 
retained cladding walls with the new bearing construction. The engineering solutions applied must involve the natural situation when both parts - the existing one and the newly constructed one (expansion joint) - settle down independently. One should also prevent the possibility that the load is shifted from the newly designed part to the existing elements of the object, as well as guarantee that the facade cannot be shifted or inclined and all the joints are durable even at extremely unfavorable external conditions, such as: high temperature or powerful suction of the wind.

The high quality of the space designed results from the favorable climate of the interiors, which can be achieved by a proper acoustic and thermal insulation in the rooms guaranteed. As for the buildings of an important historical and architectural value whose outer elevation must not be changed, it is likely that the only permitted solution while carrying out their adaptation would be the thermal insulation of the building envelope only from the inside. The market of building materials is now offering a lot of confirmed technological solutions that can improve the parameters of the outer partitions along with eliminating the risk of too high humidity resulting from a high condensation of steam. The most effective solution is to apply the specialist's blocks made of autoclaved cellular concrete. They improve the thermal parameters of the walls and prevent the condensation, fungi and mold, and do not require any additional moisture insulation layer to be applied. The blocks are characterized by a high steam permeability, as well as accumulation qualities of the material they are built of [5].

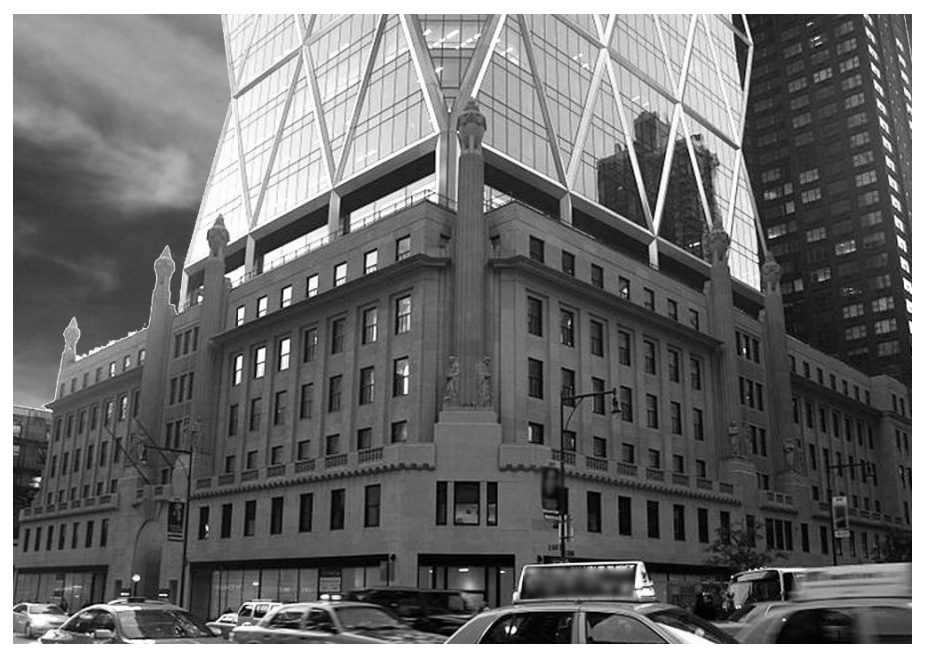

Fig. 5. Hearst Tower, New York, USA (Source: Author's photo of July 2010)

A good example confirming that the retaining of the existing facade can be fully comforted with the contemporary requirements for the energy consumed by the building is the realization of the Hears Tower in New York. The load-bearing construction of this high-rise has been executed in a new technology making it possible to save $20 \%$ of the construction steel comparing to the conventional solutions. $80 \%$ of the steel used came from recycling. The building, in which the facade was saved, consumes $25 \%$ less energy than the neighboring high-rise objects carried out fully with the use of high-tech methods [6]. 


\section{Conclusion}

The adapting of the buildings that were withdrawn from using and are now to be adapted to a new function can be fairly understood as an example of green architecture. Contrary to the demolition of buildings, it appears to be significantly less destructive for the natural environment and at the same time makes it possible to improve the standard of living for the people who still inhabit the worn-out urban tissue. Yet, the main drawback of the modernization process executed in empty building is its high cost (compared with the object built from scratch), as well as an extended investment process. The re-consuming of external walls or partitions ought to respect the principles applied to the monuments conservation and general building craft. Any construction or building work done in the objects withdrawn from exploitation should be preceded by a detailed examination of the technical condition of the load-bearing structure. Also, the materials should be examined in order to define their mechanical properties. While the adaptation and modernization work is being done, it is necessary to guarantee the security of the construction at every stage of the work, i.e. to secure the existing construction so that the work planned could be started, as well as during the replacement of the bearing system and all the time when the investment is executed- up to the securing of the destination object with its construction system adapted to a new usable function.

The "facadism"- a colloquial label defining the idea of retaining outer walls of the building- may be understood as a kind of compromise between: the tradition and contemporary time, or the demolition and the retention of the existing building, or the investor who would like to achieve a modern space that meets the needs of contemporary maintenance along with designer's trends and the local planning authority who wants to preserve the original form of the building. As a consequence, the deserted buildings can be revived, their functionality and aesthetic values improved, the quality of living and the comfort of interiors in respect of comfortable using enhanced, with the preserving of the compact urban tissue. The issues referring to such ideas as: the improving of the technical and maintenance conditions of the existing facades, combining modern hightech constructions with traditional structures of significantly lower parameters, as well as the ability to preserve the monumental values while an adaptation of the object is being done, mount a serious challenge to contemporary designers.

\section{References}

1. Gibb, A.G.F., Sher, W.D.: Technical and Managerial Challenges of Façade Retention. In: Proceedings of The Institution of Civil Engineers- Strctures and Buildings, pp. 219-229. Thomas Telford Services LTD, London (1999)

2. Polish Green Building Council (2012), http: / / www .plgbc . org • pl

3. Dimitrokali, E., Hartungi, R., Howe, J.: Sustainable Conservation and Façade Retention Developments in Historic Cities. In: Proceedings of The 16th Annual International Sustainable Development Research Conference, Paper 109, Hong Kong (2010)

4. Engel, P.: Techniki Podpierania, Wzmacniania Tymczasowego lub Trwalego z Wykorzystaniem Stali (2012), http: / / www . constructalia.com

5. Silka \& Ytong (2012), http://www.ytong-silka.pl

6. http://www.wikipedia.org (2012) 